\title{
Review
}

\section{Role of p73 in malignancy: tumor suppressor or oncogene?}

\author{
T Stiewe ${ }^{1}$ and BM Pützer ${ }^{\star 1}$ \\ ${ }^{1}$ Centre for Cancer Research and Cancer Therapy, Institute of Molecular \\ Biology, University of Essen, Medical School, Hufelandstr. 55, D-45122 Essen, \\ Germany \\ * Corresponding author: BM Pützer, Institute of Molecular Biology, (Cancer \\ Research), University of Essen, Medical School, Hufelandstr. 55, D-45122 \\ Essen, Germany. Tel: +49 201723 3158; Fax: +49 201723 5974; \\ E-mail: brigitte.puetzer@uni-essen.de
}

Received 10.9.01; revised 13.11.01; accepted 27.11.01

Edited by G Melino

\begin{abstract}
The recently identified p53 family member, p73, shows substantial structural and functional homology with p53. However, despite the established role of p53 as a proto-type tumor suppressor, a similar function of p73 in malignancy is questionable. Overexpression of $p 73$ can activate typical p53responsive genes, and activation of $p 73$ has been implicated in apoptotic cell death induced by aberrant cell proliferation and some forms of DNA-damage. These data together with the localization of TP73 on chromosome 1p36, a region frequently deleted in a variety of human tumors, led to the hypothesis that p73 has tumor suppressor activity just like p53. However, unlike p53- $I-$ mice, p73 knockout mice do not develop tumors. Extensive studies on primary tumor tissues have revealed overexpression of wild-type p 73 in the absence of $p 73$ mutations instead, suggesting that p73 may augment, rather than inhibit tumor development. In contrast to $\mathrm{p53}$, differential splicing of the TP73 gene locus gives rise to a complex pattern of interacting $\mathrm{p} 73$ isoforms with antagonistic functions. In fact, induction of apoptosis by increased levels of p73 can be blocked by both p53 mutants and the N-terminally truncated p73 isoforms, which were recently shown to possess oncogenic potential. In the light of these new findings the contradictory role of $\mathrm{p} 73$ in malignancy will be discussed. Cell Death and Differentiation (2002) 9, 237-245. DOI: 10.1038/ sj/cdd/4400995
\end{abstract}

Keywords: p73; p53; apoptosis; tumor suppressor; oncogene

Abbreviations: $\mathrm{LOH}$, loss of heterozygosity; $\mathrm{LOI}$, loss of imprinting; TA, transactivation domain; DBD, DNA binding domain; OD, oligomerization domain; $\mathrm{PR}$, proline-rich domain; SAM, steric alpha motif-like domain; $\triangle T A$, lacking the aminoterminal transactivation domain; RT - PCR, reverse transcriptase-polymerase chain reaction; TCR-AICD, T-cell receptor activation-induced cell death; RB, retinoblastoma tumor suppressor

\section{Introduction}

In our search for the underlying causes of cancer, TP53 is the most intensively studied gene. Integrating numerous signals that control cell life and death, p53 has evolved from a potential oncogene to the prototype tumor suppressor gene. As p53 regulates the expression of genes involved in cell cycle arrest and apoptosis in response to genotoxic damage or cellular stress, failure of p53 function consequently leads to uncontrolled cell growth - a defining feature of cancer cells. ${ }^{1}$ It is therefore no wonder that p53 is the most frequent site of genetic alterations found in human cancers. ${ }^{2}$ For almost two decades, p53 made scientists believe that it is unique in form and function. Therefore, the recent discovery of two TP53related genes, TP73 and TP63 (KET, TP51, p40, p73L, and $A / S)$, raised the possibility that other tumor suppressors exist which share the power of p53 in preventing cancer formation. ${ }^{3-5}$ This review gives a summary of our current knowledge about the curious role of p73 in malignancies and discusses possible diagnostic and therapeutic implications.

\section{TP73 gene locus: complexity of isoforms}

p63 and p73 contain the characteristic features of the p53 protein-an acidic, aminoterminal transactivation (TA) domain, a proline-rich domain (PR), a central core DNA-binding (DBD) and a carboxy-terminal oligomerization domain (OD). ${ }^{3}$ Consistently, p73 showed many p53-like properties: it could bind to p53 DNA target sites, transactivate p53-responsive genes and induce cell cycle arrest or apoptosis. ${ }^{3,6-8}$

\section{C-terminal diversity}

Unlike the TP53 gene, which shows only little alternative splicing, both TP63 and TP73 give rise to a complexity of multiple protein isoforms due to alternative promoter usage ${ }^{8,9}$ and differential mRNA splicing (Figure 1A). ${ }^{3,10-14}$ Most of the alternative splicing occurs at the $3^{\prime}$ end, involves exons 10 to 13 , and generates transcripts encoding protein isoforms with different C-terminal structures (Figure 1B). At present, at least six alternatively spliced p73 mRNAs named $\alpha, \beta, \gamma, \delta, \varepsilon$, and $\zeta$ have been identified in normal cells that share the $\mathrm{N}$-terminal transactivation domain, the DNA-binding domain and the oligomerization domain. In addition, the recently discovered short isoforms $\theta, \eta$, and $\eta 1$ lack the p73 C-terminal transactivation domain and the oligomerization domain encoded by exon $10 .^{15}$ In contrast to all other C-terminal isoforms, the $\eta$ isoform has so far only been detected in neoplastic but not in normal cells. ${ }^{15}$ The existence of several C-terminal splice variants with completely different C-terminal sequence motifs is an intriguing feature of $p 73$, yet the specific function of these different p73 isoforms, if any, is still unknown. What makes the complexity of $\mathrm{C}$-terminal isoforms even more difficult to assess is, that none of the smaller 
A
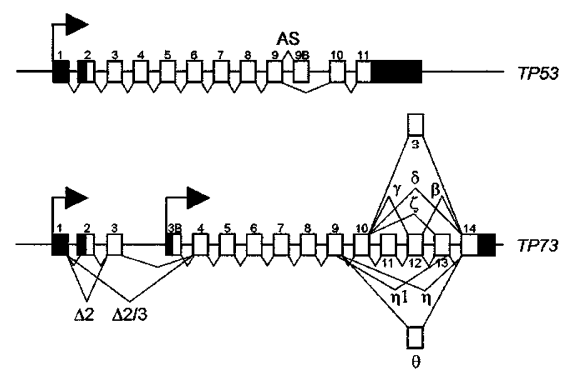

B

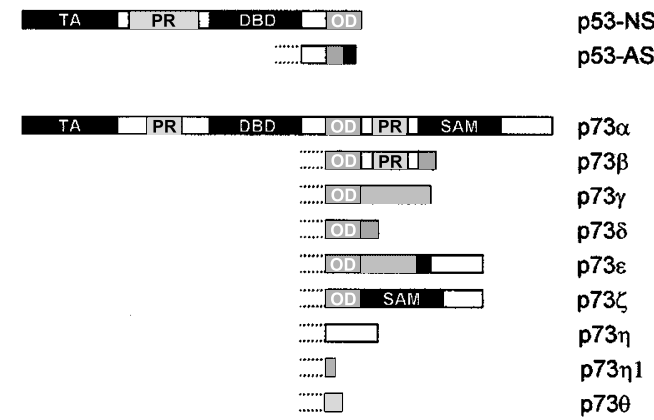

C

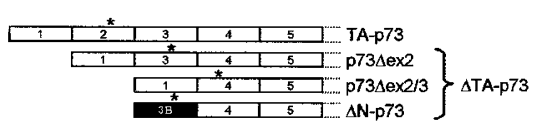

MAQSTATSPDGGTTEEHLWS 20 LEPDSTYFDLPQSSRGNNEVVGGT TA-P73

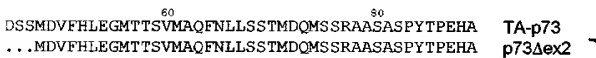

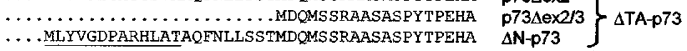

Figure 1 Gene structure of TP53 and TP73. (A) TP53 generates two splice variants, p53-NS (normal splice) and p53-AS (alternative splice). TP73 Cterminal isoforms $\alpha, \beta, \gamma, \delta, \varepsilon, \zeta, \eta, \eta 1$, and $\theta$ are generated by alternative splicing of exons 10 to 14 . TP73 $\mathrm{N}$-terminal isoforms comprise full-length (transactivating) TA-p73 and N-terminally truncated p73 isoforms $\Delta T A-p 73$

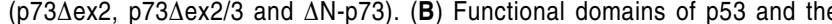
various $C$-terminal p73 protein isoforms. The transactivation (TA), DNA binding (DBD), oligomerization (OD), steric alpha motif-like (SAM), and proline-rich (PR) domains are shown. Alternative splice p53 undergoes splicing, which results in a replacement of p53 amino acids 364-390 with 17 unique amino acids. Identical amino acid sequence motifs in the different p73 C-terminal regions are indicated by equal shading. (C) N-terminal TP73 splicing pattern (upper half) and amino acid alignment of $\Delta T A-p 73$ proteins (lower half). The underlined amino acids are unique to the $\triangle T A-p 73$ isoforms $\Delta \mathrm{N}-\mathrm{p} 73$ and are derived from the alternative exon $3 \mathrm{~B}$ located in intron 3 . The translations start is indicated $\left({ }^{*}\right)$

isoforms has been detected on the protein level-so far all experimental evidence of these $\mathrm{C}$-terminal isoforms is based on detection by RT-PCR. Current commercially available antibodies only react with $p 73 \alpha$ and $p 73 \beta$ and these two isoforms are therefore the only ones that have been detected unambiguously on the protein level.

\section{N-terminal diversity}

In addition to the carboxy-terminal diversity reported for human p73, the analysis of murine p73 by Yang et al. ${ }^{16}$ revealed a transcript $(\Delta \mathrm{N}-\mathrm{p} 73)$ that lacks the $\mathrm{N}$-terminal transactivation domain and is derived from an alternative promoter located in intron 3. Recently, the human homologue (termed $\Delta \mathrm{N}-\mathrm{p} 73$ ) transcribed from an alternative promoter was identified. ${ }^{17}$ Apart from this physiological transcript, $\mathrm{N}$-terminally truncated p73 proteins in cancer cells are also encoded by N-terminal splice variants that lack either exon 2 or both exon 2 and 3 (Figure 1C) (Stiewe and Pützer, unpublished data). ${ }^{3,12,14,18}$ Together, in human cancer cells three different p73 messages (p73 $\Delta$ ex2, p73 $\Delta$ ex2/3 and $\Delta N-p 73$ ) encode $\mathrm{N}$-terminally truncated p73 proteins (designated $\Delta T A-p 73$ ). However, the relative contribution of these transcripts to the expression of the $\mathrm{N}$-terminally truncated $\mathrm{p} 73$ proteins that could be identified in human tumor cell extracts is not clear at present (Stiewe and Pützer, unpublished data). Since the N-terminal domain harbors the major transactivation domain of $p 73$, the $\Delta T A$ p73 isoforms are all transactivation-defective and act as dominant-negative inhibitors of full-length $p 73$ and p53. By antagonizing the pro-apoptotic p53 family members the $\Delta T A$ p73 isoforms serve as anti-apoptotic proteins. ${ }^{9}$ Therefore, the use of two different promoters combined with alternative splicing yields essentially two classes of proteins: those containing an acidic amino terminus (TA-p73) analogous to the transactivation domain of p53; and those with a truncated amino terminus ( $\triangle T A-p 73$ ) that lack this region. Inherent to this unusual gene structure is the idea of 'two genes in one', whereby TA-p73 products embody the necessary pieces for p53-like function, whereas $\Delta T A-p 73$ products act entirely opposite. ${ }^{8}$ With regard to human cancer it is therefore an eminent question, whether p73 acts p53-like as a tumor suppressor or rather opposite as an oncogene.

\section{Signaling by $\mathrm{p} 73$}

The ability of p53 to inhibit cell growth is due, at least in part, to its ability to bind to specific DNA sequences and activate the transcription of target genes which encode proteins involved in cell cycle control (e.g. CDKN1A/p21, GADD45, HDM2, PCNA, 14-3-3 $\sigma, B T G 2)$ and apoptosis (e.g. BAX, KILLER/ $D R 5$, redox-related p53-induced genes like PIG3, NOXA, PIDD, PUMA, p53AIP1). ${ }^{1}$ When overexpressed p73 also binds to p53 DNA target sites, transactivates p53-responsive genes and is capable of inducing cell cycle arrest and apoptosis in mammalian cells in a p53-like manner. ${ }^{3,6,7}$ The effects of p73, however, appear to be cell-context dependent, as Fang et al. ${ }^{19}$ showed that induced expression of both $p 73 \alpha$ and $\mathrm{p} 73 \beta$ can also lead to irreversible growth arrest with markers of replicative senescence in EJ bladder carcinoma cells. However, most of these studies relied on overexpression of p73 in cells, therefore possibly masking subtle differences between the various p53 family members. In addition, there are no reports confirming binding of endogenous p73 to potential target gene promoters by chromatin immunoprecipitation in vivo.

Nonetheless, there is evidence that p73 can activate many but not all of the previously identified p53 cellular target genes. ${ }^{20}$ For example $14-3-3 \sigma$ is strongly induced by p73, whereas p21 and HDM2 are strongly induced by p53. ${ }^{20}$ This raises the possibility that target genes exist, that are specifically regulated by $p 73$ but not by $p 53$, which would provide new insight into nonredundant functions of 
the p53 family members. A first step in this direction was the identification of aquaporin $3(A Q P 3)$, a glycerol and water transporter, as a p73-responsive gene using a cDNA subtraction method. It is speculated, that in p73-deficient mice lack of $A Q P 3$ induction accounts for the defects in production or reabsorption of cerebrospinal fluid, resulting in hydrocephalus. ${ }^{21}$ Common p53/p73-target genes on the one hand and experimental evidence for exclusive p73- (or p53-) targets on the other hand indicate, that p73 in general appears both similar to and different from p53 in its signaling pathways.

Furthermore, there is evidence from several reports indicating a quantitative difference in the transcriptional activity of the various p73 splice variants. In many assays, for example, the $\beta$-isoform is a more potent transcriptional activator than $\mathrm{p} 73 \alpha^{10,20,22,23}$ Likewise $\mathrm{p} 73 \beta$ is more potent than $p 73 \alpha$ as an inducer of apoptosis, suggesting that $p 73 \alpha$ contains an 'inhibitory' region not included in the $\beta$-isoform. Consistently, a C-terminal deletion mutant of p73 $\alpha$ lacking the putative inhibitory region showed a significantly higher level of transcriptional activity than wild-type $p 73 \alpha$. $^{24,25}$ Moreover, the transcriptional activity of $\mathrm{p} 73 \beta$ was reduced in trans by co-expression with either $\mathrm{p} 73 \alpha$ or $\mathrm{p} 73 \varepsilon$, which bears an identical C-terminal structure as $p 73 \alpha .^{25}$ This suppression effect is most likely mediated by inter-variant associations as it depends on the presence of the oligomerization domain. These observations indicate that p73-mediated gene expression is regulated by the interaction of all p73 isoforms present in the cell. The current data therefore indicate the existence of transciptional specificity among the p53-family members with pronounced differences between p53 and p73 on the one hand and between the various $p 73$ isoforms on the other hand.

\section{p73 in cancer}

The data presented above all demonstrate that signaling by p73 is different yet similar to what is known for p53, suggesting a comparable function as a tumor suppressor gene in human cancers. However, these data cannot easily be reconciled with data obtained from knock-out mice.

\section{p73 knockout mice}

p73-deficiency causes profound developmental defects, including hippocampal dysgenesis, hydrocephalus, chronic infections and inflammation, as well as abnormalities in pheromone sensory pathways revealing a unique role for p73 in neurogenesis, sensory pathways and homeostatic control. ${ }^{16}$ However, in contrast to p53-deficient mice, which develop spontaneous tumors at high frequencies in various organs, ${ }^{26}$ those lacking p73 show no increased susceptibility to spontaneous tumorigenesis. ${ }^{16}$ At first sight, these data argue against a tumor suppressor activity of $p 73$, but it has to be kept in mind, that p73 encodes two antagonistic genes in one-TA-p73 and $\Delta \mathrm{N}$-p73. The knockout mice lack both p73 isoforms so that the relative balance of pro- and anti-apoptotic isoforms remains unchanged. Studies of knockout mice in which specific isoforms, such as full-length or $\Delta \mathrm{N}-\mathrm{p} 73$, are deleted, should provide further insight into the unique functions of each isoform and might disclose a specific function of one or the other isoform in tumorigenesis.

\section{Loss of heterozygosity and imprinting}

The mouse p73 gene maps to the distal part of chromosome 4 , which undergoes frequent loss of heterozygosity in $\gamma$ radiation-induced T-cell lymphomas. ${ }^{27}$ The human TP73 gene maps to chromosome 1p36.3, a region commonly deleted in various tumor entities including neuroblastoma, colorectal cancer, melanoma and breast cancer. ${ }^{3}$ Fine mapping studies on the TP73 locus confirmed its localization within the smallest region of overlap (SRO), ${ }^{28}$ prompted the assumption that p73 was indeed the 1p36 tumor suppressor gene long sought after and initiated an extensive analysis of the p73 status of more than 1000 primary tumors (Table 1). Unfortunately, the majority of studies failed to detect mutations in both cell lines and tumors, including tumors with 1 p36 deletions, emphasizing that p73 is no classical tumor suppressor according to Knudson's two-hit hypothesis. Initially, the failure to detect mutations in the remaining allele was interpreted with the localization of the TP73 gene in an imprinting region explaining the monoallelic expression of $p 73$ observed in many normal tissues. ${ }^{3}$ If true, loss of the transcribed allele, such as through 1p36 deletion, would be sufficient to make a cell functionally null for p73. However, although some studies demonstrated monoallelic expression in certain tissues and tumors, a number of different studies have demonstrated loss of imprinting (LOI), biallelic expression of p73 or allele switching (Table 1). Thus, information about the imprinting of p73 in cancers is still limited and confusing. If LOI is a common event, p73 might even function to enhance tumor cell growth like an oncogene.

\section{Promoter silencing}

Loss of p73 expression appears to be an unfrequent finding in general. Transcriptional silencing due to promoter hypermethylation has only been reported in certain hematological malignancies such as primary acute lymphoblastic leukemias (ALLs) and Burkitt lymphomas. ${ }^{29,30}$ In contrast, increased expression of p73 was reported in chronic myelogenous leukemia blast crisis, acute myelogenous leukemia, and B-cell chronic lymphocytic leukemias (B-CLL) with a positive correlation of 7 73overexpression and a high-riskB-CLL phenotype. ${ }^{31,32}$

\section{Mutations of p73 in primary cancers}

Despite extensive studies of p73 in a variety of primary cancers, only few tumors with missense mutation of p73 have been found (Table 1). For example, two mutations (P405R and $P 425 \mathrm{~L}$ ), one somatic and one germline, were found in primary neuroblastoma. The $\mathrm{P} 425 \mathrm{~L}$ substitution reduced the ability of $p 73 \alpha$ to transactivate various p53-responsive promoters and to suppress cell growth in p53-deficient Saos-2 cells. In contrast, p73 $\beta$ (P425L) was as effective as wild-type $p 73 \beta$ in transactivation and growth inhibition. On the other hand, the P405R substitution had no significant effect on both the transcriptional activity and the growth-suppressive ability of $p 73 \alpha$ or $p 73 \beta .^{33}$ The lack of correlation between the 
Table 1 Loss of heterozygosity, mutation and expression level in p73 in primary cancers

\begin{tabular}{|c|c|c|c|c|}
\hline Cancer type & Mutations & $\begin{array}{l}\text { Expression } \\
\text { level }^{c}\end{array}$ & $\mathrm{LOH}^{\mathrm{a}}$ & $\begin{array}{l}\text { Imprinting } \% \\
\text { methylation }\end{array}$ \\
\hline \multicolumn{5}{|l|}{ Neuroblastoma } \\
\hline Kovalev 1998, Cell Growth Differ. 9: 897 & $0 / 16$ & $\mathrm{~T}>\mathrm{N}$ & & B $5 / 6$ \\
\hline Ichimiya 1999, Oncogene 18: 1061 & 2/140 (P405R, P425L) & & $28 / 151$ & \\
\hline Ejeskar 1999, Int. J. Mol. Med. 3: 585 & $0 / 30$ & & $10 / 30$ & \\
\hline Han 1999, Eur. J. Surg. Oncol. 25: 194 & $0 / 23$ & & & \\
\hline Liu 2000, Int. J. Oncol. 16:181 & $0 / 31$ & & & B $4 / 8$ \\
\hline Yang 2000, Int. J. Mol. Med. 5:379 & $0 / 30$ & & $5 / 33$ & \\
\hline Kong 2000 , Neoplasia $1: 80$ & $0 / 32$ & & $3 / 32$ & \\
\hline Matos 2001, Pediatr. Hematol. Oncol. 18: 37 & & $\mathrm{~T}>\mathrm{N}$ & & B $7 / 11$ \\
\hline \multicolumn{5}{|l|}{ Lung cancer } \\
\hline Nomoto 1998, Cancer Res. 58: 1380 & $0 / 44$ & & $11 / 26$ & B 25/26 \\
\hline Mai 1998, Cancer Res. 58: 2347 & $0 / 21$ & $\mathrm{~T}>\mathrm{N}(9 / 10)$ & & $\mathrm{M} \mathrm{5/10}$ \\
\hline Ikawa 1999, Cell Death Differ. 6: 1154 & $1 / 36(P 405 R)$ & & $11 / 33$ & \\
\hline Tokuchi 1999, Br. J. Cancer 80: 1623 & $0 / 3$ & $\mathrm{~T}>\mathrm{N}(52 / 60)$ & & \\
\hline \multicolumn{5}{|l|}{ Colorectal cancer } \\
\hline Sunahara 1998, Int. J. Oncol. 13: 319 & $0 / 82$ & $\mathrm{~T}>\mathrm{N}$ & $8 / 46$ & \\
\hline $\begin{array}{l}\text { Han 1999, Eur. J. Surg. Oncol. 25: } 194 \\
\text { Gastric cancer }\end{array}$ & $0 / 43$ & & & \\
\hline Han 1999, Eur. J. Surg. Oncol. 25: 194 & $0 / 31$ & & & \\
\hline Yokozaki 1999, Int. J. Cancer 83: 192 & $0 / 12$ & low p73 (6/8) & $12 / 32$ & B $32 / 32$ \\
\hline Kang 2000, Clin. Cancer Res. 6: 1767 & $0 / 39$ & $T>N(14 / 16)$ & & B $5 / 21$ \\
\hline \multicolumn{5}{|l|}{ Esophageal cancer } \\
\hline Nimura 1998, Int. J. Cancer 78: 437 & $0 / 48$ & & $2 / 25$ & \\
\hline \multicolumn{5}{|l|}{ Hepatocellular carcinoma } \\
\hline Mihara 1999, Br. J. Cancer 79: 164 & $0 / 48$ & $\mathrm{~T}=\mathrm{N}$ & $5 / 25$ & \\
\hline Tannapfel 1000, J. Natl. Cancer Inst. 91: 1154 & & $T>N(61 / 193)$ & & \\
\hline Herath 2000, Hepatology 31: 601 & & $T>N$ & $14 / 35$ & \\
\hline Peng 2000, Anticancer Res. 20: 1487 & $1 / 22$ & & $2 / 11$ & $7 / 8$ \\
\hline \multicolumn{5}{|l|}{ Cholangiocellular carcinoma } \\
\hline Tannapfel 1999, Br. J. Cancer 80: 1069 & & high p73 (17/41) & & \\
\hline \multicolumn{5}{|l|}{ Renal cancer } \\
\hline Mai 1998, Oncogene 17: 1739 & $0 / 27$ & $\mathrm{~T}=\mathrm{N}$ & & $\begin{array}{l}\text { M 11/12N, B 8/12T, } \\
\text { S 2/12T }\end{array}$ \\
\hline \multicolumn{5}{|l|}{ Breast cancer } \\
\hline Zaika 1999, Cancer Res. 59: 3257 & $0 / 8$ & $\mathrm{~T}>\mathrm{N}(29 / 77)$ & & B 4/8) \\
\hline Shishikura 1999, Int. J. Cancer 84: 321 & $0 / 87$ & $\mathrm{~T}=\mathrm{N}$ & $6 / 46$ & \\
\hline Han 1999, Eur. J. Surg. Oncol. 25: 194 & $1 / 47$ (R269Q) & & & \\
\hline Scwartz 1999, Breast Cancer Res. Treat. 58: 25 & $0 / 3$ & $\mathrm{~T}>\mathrm{N}(52 / 60)$ & & \\
\hline Dominguez 2000, Breast Cancer Res. Treat. 63: 17 & & & $6 / 67$ & \\
\hline Ahomadegbe 2000, Oncogene 19: 5413 & & $\mathrm{~T}<\mathrm{N}$ & $7 / 22$ & M 12/16 \\
\hline $\begin{array}{l}\text { Dominguez 2001, Breast Cancer Res. Treat. 66: } 183 \\
\text { Prostate cancer }\end{array}$ & & $\mathrm{T}>\mathrm{N}(19 / 70)$ & $10 / 59$ & \\
\hline Takahashi 1998, Cancer Res. 58: 2076 & 0/106 & $\mathrm{T}>\mathrm{N}$ & $2 / 38$ & \\
\hline Yokomizo 1999, Prostate 39: 94 & $0 / 27$ & $\mathrm{~T}=\mathrm{N}$ & & B 27/27 \\
\hline \multicolumn{5}{|l|}{ Melanoma } \\
\hline Kroiss 1998, Melanoma res. 8: 504 & $0 / 17$ & & & \\
\hline Schittek 1999, Int. J. Cancer 82: 583 & $0 / 51$ & & $2 / 10$ & \\
\hline Herbst 1999, Arch. Dermatol. Res. 291: 362 & & & $1 / 17$ & \\
\hline \multicolumn{5}{|l|}{ Ovarian cancer } \\
\hline Imyanitov 1999, Oncogene 18: 4640 & & $\mathrm{~T}>\mathrm{N}$ & $24 / 56$ & \\
\hline Codegoni 1999, Ann. Oncol. 10:949 & & & $2 / 51$ & \\
\hline 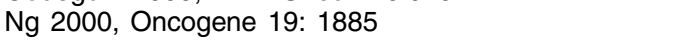 & $0 / 63$ & $\mathrm{~T}>\mathrm{N}(38 / 50)$ & $5 / 10$ & \\
\hline Zwahlen 2000, Int. J. Cancer 88: 66 & & $\mathrm{~T}>\mathrm{N}$ & & \\
\hline Chen 2000, Clin. Cancer Res. 6: 3910 & & $\mathrm{~T}>\mathrm{N}$ & $2 / 24$ & B 22/24 \\
\hline \multicolumn{5}{|l|}{ Bladder cancer } \\
\hline Yokomizo 1999, Oncogene 18: 1629 & $0 / 23$ & $\mathrm{~T}>\mathrm{N}(22 / 23)$ & & B23/23 \\
\hline \multirow{2}{*}{\multicolumn{5}{|c|}{ CNS-Tumors }} \\
\hline & & & & \\
\hline Loiseau 1999, Neurosci. Lett. 263: 173 & & $\mathrm{~T}>\mathrm{N}$ & & \\
\hline Mai 1998, Cancer Res, 59: 2791 & $0 / 20$ & & & \\
\hline Lomas 2001, Cancer Genet. Cytogenet. 129: 88 & 1/30 (N204S) & & & \\
\hline $\begin{array}{l}\text { Nozaki 2001, Brain Pathol. 11. } 296 \\
\text { Hematological malignancies }\end{array}$ & $0 / 27$ & $\mathrm{~T}>\mathrm{N}$ & & \\
\hline Corn 1999, Cancer Res. 59: 3352 & $0 / 31$ & & & $11 / 35$ methylated \\
\hline Stirewalt 1999, Leukemia 13: 985 & $0 / 60$ & & & M 6/10 \\
\hline Novak 2001, Ann. Oncol. 12: 981 & & $\mathrm{~T}>\mathrm{N}$ & & \\
\hline
\end{tabular}

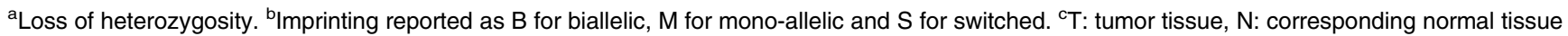


infrequent mutations and their growth-suppressive function underline that human cancers typically maintain expression of functionally active p73.

\section{Overexpression of wild-type p73}

As already mentioned above, the majority of studies that have not only analyzed the p73 status on the genomic level, but also measured p73 expression, have identified higher p73 mRNA and protein levels in tumor tissues compared with surrounding normal tissue (Table 1). Whereas levels of p73 expression are typically so low that it is often difficult to detect the transcripts by Northern blot or the protein by Western blot analysis, p73 expression among cancers is variable and some tumor cell lines and primary tumor samples express readily detectable levels (Stiewe and Pützer, unpublished data). ${ }^{34}$ In particular, neuroblastomas, ependymomas, hepatocellular and cholangiocellular carcinomas, lung, prostate, colorectal, gastric, breast, bladder, ovarian, and esophageal cancers have all been reported to have elevated p73 levels compared with their normal tissue counterparts (Table 1).

Importantly, p73 overexpression appears to be positively correlated with prognostically relevant parameters. Tannapfel et al. ${ }^{35}$ identified p73-overexpression as an independent prognostic factor in a large study of 193 patients with hepatocellular carcinomas. The mean survival time for $\mathrm{p} 73-$ positive tumors was 127 days versus 462 days for those without expression. ${ }^{35}$ Similarly, p73-overexpression correlated with advanced tumor grade in meningiomas, which are typically p53 wild-type. In low grade meningiomas p73 was undetectable in 10 of 25 cases and expressed at low levels in the remainder. In contrast, p73 expression was detectable in all malignant meningiomas. ${ }^{36}$ In breast cancer, a significant association of p73 overexpression and tumors with lymph node metastases, vascular invasion and higher pathologic stage was demonstrated. ${ }^{37}$ Likewise, p $73 \alpha$ protein expression positively correlated with higher risk B-CLL stages. ${ }^{32}$ All these correlations between high level expression of $p 73$ and various prognostic parameters make it unlikely that p73 overexpression is only secondary to other transforming events and suggest that p73 is implicated in tumorigenesis and possibly functions as a dominant oncogene to enhance tumor progression and therapeutic resistance. The first experimental evidence in this direction stems from the observation that $p 73 \alpha$ overexpression is associated with resistance to treatment with DNA-damaging agents in a human ovarian cancer cell line. ${ }^{38}$ So far, however, there are no definite answers as to (i) which p73 isoforms are actually overexpressed and ultimately responsible for the possible oncogenic activity and (ii) which factors are the underlying causes for p73 overexpression in tumor tissues.

\section{Upregulation of p73 by oncogenes}

Most human cancers harbor aberrations of cell-cycle control, which result in deregulated and elevated activity of the cellcycle promoting transcription factor E2F1. ${ }^{39}$ Deregulation of E2F1 by mitogenic oncogenes including Ras, c-myc, v-abl and $\mathrm{E} 1 \mathrm{~A}$ is believed to trigger an apoptotic checkpoint, leading to accumulation of p53 and p53-dependent apoptosis. $^{39}$ This is due, at least partly, to the induction of the tumor suppressor ARF, which in turn prevents MDM2 from targeting p53 for degradation. MDM2 binds to a sequence in the p53 Nterminal transactivation domain and, in addition to marking p53 for destruction, prevents p53 from serving as a transcriptional activator. MDM2 also inhibits both p73 dependent transactivation and p73 dependent apoptosis, ${ }^{40,41}$ however, in contrast to p53, MDM2 binding does not lead to p73 degradation, so that oncogenic activation of the ARF/ MDM2 pathway results in the accumulation of p53 but not p73. Whereas p53 is indirectly activated in response to oncogenes such as E2F1, we and others have recently shown, that E2F1 regulates p73 levels directly, through recognition and transactivation of the TP73 promoter which contains several E2F-binding sites. ${ }^{42,43}$ Further evidence that p73 is regulated by E2F1 includes the observation that p73 levels fall as cells are induced to exit the cell cycle after serum withdrawal and reaccumulates upon S-phase entry, a period in the cell cycle in which E2F-responsive genes are actively transcribed. ${ }^{42,43}$ E2F1-mediated p73 upregulation leads to activation of the p73 transcription function, as shown by p73responsive reporter activity and by induction of known endogenous p73 target genes. ${ }^{42}$ Importantly, E2F1-mediated activation of endogenous p73 induces apoptosis in human tumor cells and conversely, inactivation of $p 73$ by a dominant negative p73 inhibitor, a p73 anti-sense construct or expression of dominant-negative mutant p53 inhibits E2F1induced apoptosis. ${ }^{42}$ p73-/- MEFs were equally protected from E2F1-induced apoptosis as MEFs lacking $p 53^{43}$ and, unlike $p 53$, activation of $\mathrm{p} 73$ by E2F1 is also required for TCRAICD (T-cell receptor activation-induced cell death) in lymphocytes. ${ }^{44}$ In addition, other oncogenes including E1A and c-myc were also shown to signal to p73 in vivo and to enlist p73 to induce apoptosis in tumor cells. ${ }^{45}$ Analyses of E1A mutants indicated that the apoptotic activity of E1A in the absence of functional p53 correlates closely with the ability to bind the key regulators of E2F1-induced apoptosis, p300/CBP and RB. ${ }^{46}$ It is therefore conceivable, that at least the effect of E1A on p73 can be attributed to activation of E2F1. However, it still remains possible that $\mathrm{E} 1 \mathrm{~A}$ and $\mathrm{c}-m y c$ exert additional effects on p73 unrelated to E2F1. Increased levels of p73 in cancer tissues might therefore be attibutable to increased transactivation of the TP73 gene by tumor-associated deregulation of E2F1 by various oncogenes.

\section{Inhibition of p73 by mutant p53}

However, since E2F1-induced upregulation of p73-expression has been shown to cause apoptosis, ${ }^{42,43}$ sustained overexpression of $\mathrm{p73}$ would therefore require inhibition of its inherent pro-apoptotic activity. This could be achieved by p53 mutants which inhibit the putative tumor suppressor action of p73 in a dominant negative fashion by generating defective heterooligomers with wild-type p73. In cotransfection assays, the $\mathrm{R} 175 \mathrm{H}$ and $\mathrm{R} 248 \mathrm{~W}$ mutants of $\mathrm{p} 53$ coprecipitate with p73 $\alpha{ }^{47}$ Furthermore, in a $p 53$ reporter assay, transactivation activity of $p 73 \alpha$ is partially inhibited by the p53 mutants, which correlates with a reduction in p73 $\alpha$-mediated apoptosis. ${ }^{47}$ The inhibition of p73-dependent transactivation and apoptosis 
appears to be mediated by direct protein - protein interaction. ${ }^{47,48}$ Initially, the high degree of homology between the oligomerization domains of p53 and p73 suggested the possiblity that these proteins may form heterotetramers, and Kaghad et al. ${ }^{3}$ reported that $\mathrm{p} 73 \beta$ but not $\mathrm{p} 73 \alpha$ can interact modestly with p53 in a yeast two-hybrid assay. However, Davison et al. ${ }^{49}$ using purified oligomerization domains of p53 and $\mathrm{p73}$, failed to find any interaction. Further studies revealed, that the core domain of mutant p53 is sufficient for the association with wild-type p73, whereas both the specific DNA binding and the oligomerization domains of p73 are required. ${ }^{50,51}$ One characteristic of $p 53$ required for its binding to p73 is recognition by the monoclonal antibody PAb240, which recognizes the p53 core domain in a mutant conformation. ${ }^{51}$ Thus, the core domain of mutant $p 53$, which has always been regarded as a 'dead' domain since it cannot bind and activate p53 target genes, now acquires a proteinprotein interaction capacity that might contribute to the gain of function activities of mutant p53 by sequestering and inactivating proteins like $p 73 .^{50}$ In addition, the association between p53 mutants and p73 is governed by a common polymorphism at codon 72 of p53 that encodes Arg or Pro, with Arg leading to a stronger interaction with p73. ${ }^{48}$ This might explain why Arg-p53 mutants cooperated with Ras to transform cells and inhibit p73-dependent apoptosis more effectively than their Pro-counterparts. Importantly, the Arg allele is preferentially mutated and retained in squamous cell tumors of the skin and vulva arising in Arg/Pro germline heterozygotes. ${ }^{48}$ Together, inactivation of $p 73$ by certain $p 53$ mutants appears to provide a selective advantage in promoting tumorigenesis.

However, reduction of p73's apoptotic potential by mutant p53 cannot account for all cases of p73 overexpression. Although e.g. in esophageal cancer samples p53 defects were significantly correlated with elevated expression of $\mathrm{p} 73,{ }^{52}$ several studies on other primary tumors have failed to find a significant correlation between p53 mutational status and p73 overexpression. In a study of Zaika et al. ${ }^{34}$ only three of eight breast cancers with p73 overexpression harbored p53 mutations, whereas five expressed wild-type p53. This mutation frequency of $38 \%$ is identical to the one determined in a group of eight randomly chosen breast cancers with normal levels of p73 expression. Similarly, no correlation between p53 mutations and p73 overexpression could be detected in lung cancers and ovarian cancer cell lines and tissues.

\section{Inhibition of p73 by specific p73-isoforms}

As described above, the TP73 gene encodes a large variety of different isoforms with in part antagonistic functions. Higher levels of total p73 mRNA and protein appear to be associated with a more complex p73 isoform pattern in ovarian cancer, ${ }^{18}$ breast cancer, ${ }^{34}$ meningiomas, B-CLL, and myeloid leukemias. Whereas in normal tissues the larger transcripts $\mathrm{p} 73 \alpha$ and $\mathrm{p} 73 \beta$ are the predominant isoforms, samples with $\mathrm{p} 73$ overexpression tend to express higher levels of the smaller transcripts $\gamma, \delta, \varepsilon$, and $\zeta . \mathrm{p} 73 \gamma$ is a very weak transcriptional activator and repressor of colony formation. ${ }^{10}$ However, although $\mathrm{p} 73 \gamma$ activates transcription poorly by itself, it has no inhibitory effect on coexpressed $\mathrm{p} 73 \beta .^{10}$ In contrast, p73 $\varepsilon$ has been shown to inhibit $\mathrm{p} 73 \beta$, which consistently is the strongest transactivator of p53 targets in ectopic expression. ${ }^{25}$ Interestingly, the epsilon isoform is expressed in leukemic cells but completely absent in mature myeloid cells. ${ }^{53}$ Since the various p73 isoforms form homotypic interactions the relative abundance of p73 isoforms in the cell certainly influences the composition of the resulting p73 tetramers and their transcriptional activity and pro-apoptotic potential, so that overexpression of the smaller variants might lead to inhibition of tumor suppressor activities of p73. However, further work on the complex regulatory network generated by the multiple C-terminal isoforms is needed in order to assess their role in tumorigenesis.

Apart from the C-terminal variants, especially the $\mathrm{N}$ terminal isoforms have to be considered as p73 inhibitors. As shown by Pozniak et al..$^{9}$ murine $\Delta \mathrm{N}-\mathrm{p} 73$ is a potent anti-apoptotic protein, which rescues sympathetic neurons from apoptosis induced by nerve growth factor (NGF) withdrawal or p53 overexpression. Murine $\Delta \mathrm{N}-\mathrm{p} 73 \beta$ interacts with p53 and inhibits p53-dependent neuronal apoptosis and because sympathetic neuron death following NGF withdrawal is p53-dependent, $\Delta \mathrm{N}$-p73 possibly inhibits neuronal apoptosis by acting as a direct antagonist to $053 .^{9}$ Consistently, p73 deficient mice, in which all p73 isoforms are deleted, display increased levels of apoptosis in developing sympathetic neurons. Apart from its function as a p53-antagonist, $\Delta \mathrm{N}-\mathrm{p} 73$ also inhibits p73-dependent transcription. ${ }^{16}$ Just recently, a human homologue of murine $\Delta \mathrm{N}-\mathrm{p} 73$, which is also transcribed from an alternative promoter in intron 3 , was identified. ${ }^{17}$

In addition, in human tumor cells $\mathrm{N}$-terminally truncated p73 proteins ( $\Delta T A-p 73)$ are also encoded by $\mathrm{N}$-terminal splice variants that lack either exon 2 or both exon 2 and 3 (Figure 1C) (Stiewe and Pützer, unpublished data). . $^{3,12,14,18}$ In an analysis of ovarian cancers expression of the p73 transcript lacking exon 2 was exclusively detected in cancer cell lines and invasive tumor tissues, but not in semimalignant borderline tumors. ${ }^{18}$ In a multifocal neuroblasto$\mathrm{ma}$, the expression pattern of the p73 $\Delta \mathrm{ex}$ transcript in different tumor areas correlated with distinct clinicobiological characteristics. ${ }^{12}$ All $\Delta$ TA-p73 isoforms were shown to have a dominant negative effect towards transactivation and apoptosis-induction by both p53 and full-length p73 (Stiewe and Pützer, unpublished data). ${ }^{14}$ Since inhibition of the tumor suppressor p53 is a common theme in human tumorigenesis and many inhibitors of p53 act as transforming oncogenes, it is intriguing to speculate that tumor progression actually selects for overexpression of the anti-apoptotic p73 isoforms. In fact, we recently demonstrated increased expression of $\Delta T A-p 73$ on the transcript and protein level in cancer cell lines and tumor tissues, which correlated with the expression level of total p73 (Stiewe and Pützer, unpublished data). Therefore, it is a very interesting observation, that the $\mathrm{N}$-terminally truncated p73 isoforms promote anchorage-independent growth of NIH3T3 cells, a characteristic feature of transformed cells. In addition, nude mice injected with STA-p73 expressing NIH3T3 cells rapidly developed tumors (Stiewe and Pützer, unpublished data). On the 
one hand, it is conceivable that $\Delta T A-p 73$ antagonizes the tumor suppressor action of p53 and its own p53-like isoform (TA-p73) either by direct competitive binding to the same cognate p53 DNA binding sites or by engaging in heteromeric complexes that are defective for specific DNA binding. On the other hand, it is also possible, that $\triangle T A-p 73$ possesses growth-promoting, potentially oncogenic activities on its own.

However, the overall effect of p73 activity in the tumor cell appears to promote transformation or tumor growth so that deregulated expression might be actively selected for during tumor development. The inherent, growth-inhibiting functions of full-length TA-p73 might be neutralized by homo- or heterotypic interactions with mutant p53, Cterminal p73 variants and/or $\Delta \mathrm{TA}-\mathrm{p} 73$, all of which are commonly found in human cancers. The resulting tumorassociated change in p73 subunit composition could account for a shift in the net function of p73 from pro- to anti-apoptotic and allow the growth-promoting, potentially oncogenic functions of p73 to outweigh the growthinhibiting, tumor suppressive activities. The current data therefore support the hypothesis that p73 acquires oncogenic activity in tumor cells (Figure 2).

\section{Conclusions and perspectives}

Starting with the identification of p73 as the first homologue of the prototype tumor suppressor p53 the prominent question has always been, whether p73 has a similar function in human malignancies as p53. The few years since p73 was brought into the p53 family have yielded impressive progress, but also important questions that need to be answered. Unfortunately, initial studies on p73 have come up with quite contradictory results. In particular, the data from ectopic p73 expression in tissue culture, together with the structural homology of p73 to p53 on the one hand, are not easily reconcilable with genetic, viral, and primary tumor data of p73, on the other hand. Is p73 a tumor suppressor gene that does not conform to Knudson's two-hit hypothesis or does p73 have oncogenic activity in the end? This duality in function appears to parallel the complexity of the TP73 gene locus with its 'two genes in one' structure. Whereas the full-length TA-p73 protein exhibits growthinhibitory, tumor suppressive functions, the anti-apoptotic $\Delta \mathrm{TA}$-isoforms act antagonistically with possible oncogenic activity. Last but not least, a further level of diversity is generated by the complexity of differential splicing at the p73 C-terminus. For future research it has to be kept in mind that there is not one single p73 protein but many different oligomeric p73 proteins with variable subunit composition. Despite the recent advances in understanding the unique roles of p73 isoforms, there are many outstanding questions. What are the unique functions of the TA and $\triangle T A$ isoforms? How is p73-mediated gene expression regulated by the interaction with (mutant) p53 and p73 splicing variants in the cell? What are the patterns of p73 isoform expression during both normal development and tumorigenesis? Understanding

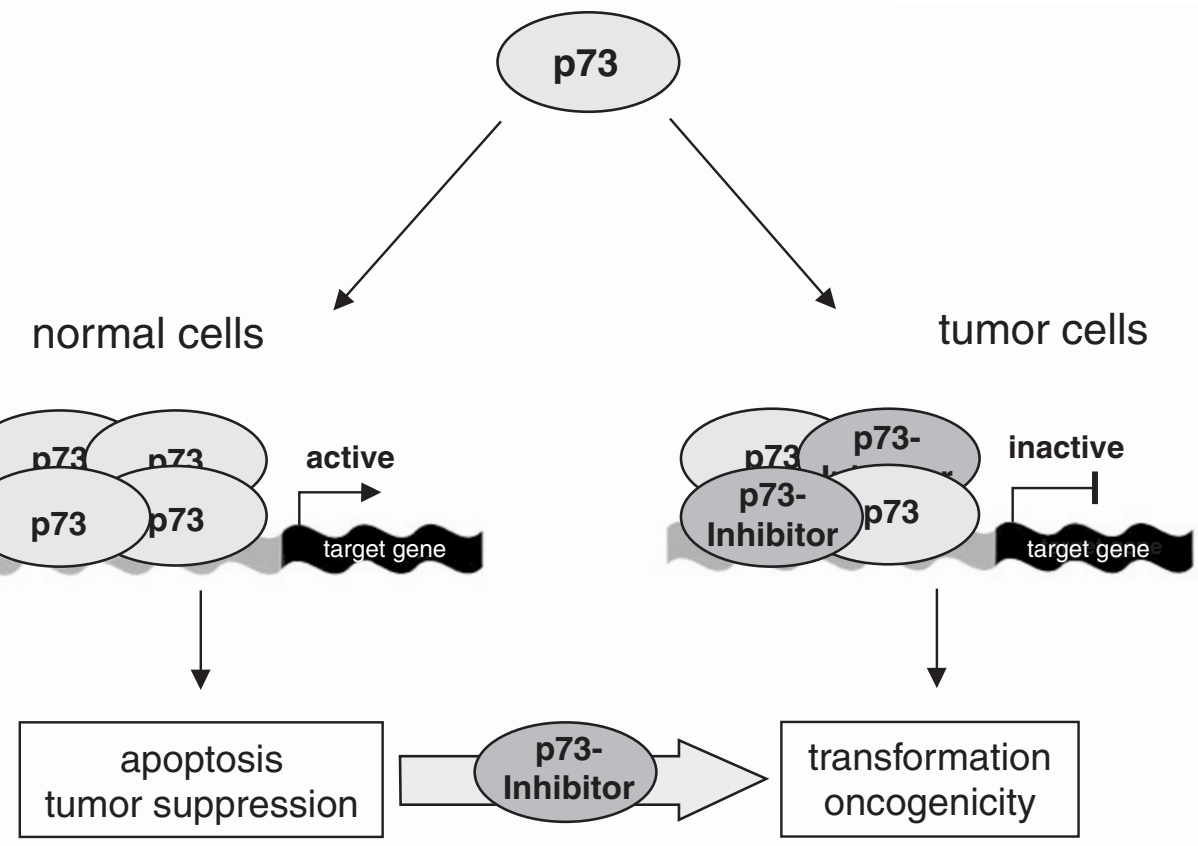

$$
\begin{aligned}
& \text { expression of p73-Inhibitors: } \\
& \text { - mutant p53 } \\
& \text { - } \Delta N-p 73 \\
& \text { - C-terminal p73-variants (e.g. p73ع) }
\end{aligned}
$$

Figure 2 Model of p73 function in human malignancies. Expression of p73-inhibitors (mutant p53, $\Delta$ TA-p73 and C-terminal p73 variants) converts pro-apoptotic, tumor suppressive p73 tetramers into growth-promoting, oncogenic p73 complexes 
the complexity of these interactions may not only allow to delineate the function of p73 in human tumorigenesis but may also enable the development of new cancer therapeutics. Overall, it becomes increasingly clear, that p73-no matter whether tumor suppressor or oncogene-is not just a relative of p53, but has developed an identity on its own.

\section{Acknowledgements}

We thank the members of the Pützer laboratory for helpful criticsms of this review. This work was supported in part by grants from the Deutsche Krebshilfe, Dr. Mildred Scheel Stiftung and the Deutsche Forschungsgemeinschaft to BM Pützer.

\section{References}

1. Vogelstein B, Lane D and Levine AJ (2000) Surfing the p53 network. Nature 408 : $307-310$

2. Hollstein M, Sidransky D, Vogelstein B and Harris CC (1991) p53 mutations in human cancers. Science 253: 49-53

3. Kaghad M, Bonnet H, Yang A, Creancier L, Biscan JC, Valent A, Minty A, Chalon P, Lelias JM, Dumont X, Ferrara P, McKeon F and Caput D (1997) Monoallelically expressed gene related to $\mathrm{p} 53$ at $1 \mathrm{p} 36$, a region frequently deleted in neuroblastoma and other human cancers. Cell 90: 809-819

4. Trink B, Okami K, Wu L, Sriuranpong V, Jen J and Sidransky D (1998) A new human p53 homologue. Nat. Med. 4: 747-748

5. Yang A, Kaghad M, Wang Y, GillettE, Fleming MD, Dotsch V, Andrews NC, Caput $D$ and McKeon F (1998) p63, a p53 homolog at 3q27-29, encodes multiple products with transactivating, death-inducing, and dominant-negative activities. Mol. Cell. 2: 305-316

6. Jost CA, Marin MC and Kaelin WG (1997) p73 is a simian [correction of human] p53-related protein that can induce apoptosis. Nature 389: 191-194

7. Ishida S, Yamashita T, Nakaya U and Tokino T (2000) Adenovirus-mediated transfer of p53-related genes induces apoptosis of human cancer cells [published erratum appears in Jpn J Cancer Res 2000 Jul;91(7):767] Jpn. J. Cancer Res. 91: 174-180

8. Yang A and McKeonF(2000) P63 and P73: P53 mimics, menaces and more. Nat. Rev. Mol. Cell. Biol. 1: 199-207

9. Pozniak CD, Radinovic S, Yang A, McKeon F, Kaplan DR and MillerFD (2000)An anti-apoptotic role for the 533 family member, p73, during developmental neuron death. Science 289: 304-306

10. De Laurenzi V, Costanzo A, Barcaroli D, Terrinoni A, Falco M, AnnicchiaricoPetruzzelli M, Levrero M and Melino G (1998) Two new p73 splice variants, gamma and delta, with different transcriptional activity. J. Exp. Med. 188: 1763 1768

11. De Laurenzi V, Catani MV, Terrinoni A, Corazzari M, Melino G, Costanzo A, Levrero M and Knight RA (1999) Additional complexity in p73: induction by mitogens in lymphoid cells and identification of two new splicing variants epsilon and zeta. Cell. Death Differ. 6: 389-390

12. Casciano I, Ponzoni M, Lo CC, Tonini GP and Romani M (1999) Different p73 splicing variants are expressed in distinct tumour areas of a multifocal neuroblastoma. Cell. Death Differ. 6: 391-393

13. Kong XT, Valentine VA, Rowe ST, Valentine MB, Ragsdale ST, Jones BG Wilkinson DA, Brodeur GM, Cohn SL and Look AT (1999) Lack of homozygously inactivated $\mathrm{p} 73$ in single-copy MYCN primary neuroblastomas and neuroblastoma cell lines. Neoplasia. 1:80-89

14. Fillippovich I, Sorokina N, Gatei M, Haupt Y, Hobson K, Moallem E, Spring K Mould M, McGuckin MA, Lavin MF and Khanna KK (2001) Transactivationdeficient p73alpha (p73Deltaexon2) inhibits apoptosis and competes with p53. Oncogene 20: $514-522$

15. Scaruffi P, Casciano I, Masiero L, Basso G, Romani Mand Tonini GP (2000) Lack of p73 expression in mature B-ALL and identification of three new splicing variants restricted to pre $B$ and C-ALL indicate a role of p73 in B cell ALL differentiation. Leukemia 14:518-519
16. Yang A, Walker N, Bronson R, Kaghad M, Oosterwegel M, Bonnin J, Vagner C, Bonnet H, Dikkes P, Sharpe A, McKeon F and CaputD (2000) p73-deficient mice have neurological, pheromonal and inflammatory defects but lack spontaneous tumours. Nature 404: 99-103

17. Sayan AE, Sayan BS, Findikli N and Ozturk M (2001) Acquired expression of transcriptionally active p73 in hepatocellular carcinoma cells. Oncogene 20: $5111-5117$

18. Ng SW, Yiu GK, Liu Y, Huang LW, Palnati M, Jun SH, Berkowitz RS and Mok SC (2000) Analysis of p73 in human borderline and invasive ovarian tumor. Oncogene 19: 1885-1890

19. Fang L, Lee SW and Aaronson SA (1999) Comparative analysis of $p 73$ and $p 53$ regulation and effector functions. J. Cell. Biol. 147: 823-830

20. Zhu J, Jiang J, Zhou W and Chen X (1998) The potential tumor suppressor p73 differentially regulates cellular 553 target genes. Cancer Res. 58: 5061-5065

21. Zheng $X$ and Chen $X$ (2001) Aquaporin 3, a glycerol and water transporter, is regulated by $p 73$ of the $p 53$ family. FEBS Lett. $489: 4-7$

22. Lee CW and La TN (1999) Promoter specificity and stability control of the p53related protein p73. Oncogene 18: 4171-4181

23. Yu J, Zhang L, Hwang PM, Rago C, Kinzler KW and Vogelstein B (1999) Identification and classification of p53-regulated genes. Proc. Natl. Acad. Sci. USA 96: 14517-14522

24. Ozaki T, Naka M, Takada N, Tada M, Sakiyama S and Nakagawara A (1999) Deletion of the $\mathrm{COOH}$-terminal region of p73alpha enhances both its transactivation function and DNA-binding activity but inhibits induction of apoptosis in mammalian cells. Cancer Res. 59: 5902-5907

25. Ueda Y, Hijikata M, Takagi S, Chiba T and Shimotohno K (2001) Transcriptional activities of p73 splicing variants are regulated by inter-variant association. Biochem. J. 356: 859-866

26. Jacks T, Remington L, Williams BO, Schmitt EM, Halachmi S, Bronson RT and Weinberg RA (1994) Tumor spectrum analysis in p53-mutant mice. Curr. Biol. 4: $1-7$

27. Herranz M, Santos J, Salido E, Fernandez-Piqueras J and Serrano M (1999) Mouse 73 gene maps to the distal part of chromosome 4 and might be involved in the progression of gamma-radiation-induced T-cell lymphomas. Cancer Res. 59: 2068-2071

28. Perri P, Praml C, Savelyeva L, Pillmann A and Schwab M (1999) Fine mapping of distal $1 p$ loci reveals TP73 at D1S468. Cytogenet. Cell Genet. 84: 111-114

29. Corn PG, Kuerbitz SJ, van NM, Esteller M, Compitello N, Baylin SB and Herman JG (1999) Transcriptional silencing of the p73 gene in acute lymphoblastic leukemia and Burkitt's lymphoma is associated with $5^{\prime} \mathrm{CpG}$ island methylation. Cancer Res. 59: 3352-3356

30. Kawano S, Miller CW, Gombart AF, Bartram CR, Matsuo Y, Asou H, Sakashita A, Said J, Tatsumi E and Koeffler HP (1999) Loss of p73 gene expression in leukemias/lymphomas due to hypermethylation. Blood 94: 1113-1120

31. Peters UR, Tschan MP, KreuzerKA, Baskaynak G, Lass U, Tobler A, Fey MF and Schmidt CA (1999) Distinct expression patterns of the p53-homologue p73 in malignant and normal hematopoiesis assessed by a novel real-time reverse transcription-polymerase chain reaction assay and protein analysis. Cancer Res. 59: 4233-4236

32. Novak U, Grob TJ, Baskaynak G, Peters UR, Aebi S, Zwahlen D, Tschan MP, Kreuzer KA, Leibundgut EO, Cajot JF, Tobler A and Fey MF (2001) Overexpression of the p73 gene is a novel finding in high-risk B-cell chronic lymphocytic leukemia. Ann. Oncol. 12: 981-986

33. Naka M, Ozaki T, Takada N, Takahashi M, Shishikura T, Sakiyama S, Tada M, Todo S and Nakagawara A (2001) Functional characterization of naturally occurring mutants (P405R and P425L) of p73alpha and p73beta found in neuroblastoma and lung cancer. Oncogene 20: 3568-3572

34. Zaika AI, Kovalev S, Marchenko ND and Moll UM (1999) Overexpression of the wild type p73 gene in breast cancer tissues and cell lines. Cancer Res. 59:32573263

35. Tannapfel A, Wasner M, Krause K, Geissler F, Katalinic A, Hauss J, Mossner J, Engeland $\mathrm{K}$ and Wittekind $\mathrm{C}$ (1999) Expression of p73 and its relation to histopathology and prognosis in hepatocellular carcinoma. J. Natl. Cancer Inst. 91: $1154-1158$

36. Nozaki M, Tada M, Kashiwazaki H, Hamou MF, Diserens AC, Shinohe $Y$, Sawamura Y, Iwasaki Y, de TN and Hegi ME (2001) p73 is not mutated in meningiomas as determined with a functional yeast assay but $p 73$ expression increases with tumor grade. Brain Pathol. 11: 296-305 
37. Dominguez G, Silva JM, Silva J, Garcia JM, Sanchez A, Navarro A, Gallego I, Provencio M, Espana P and Bonilla F (2001) Wild type p73 overexpression and high-grade malignancy in breast cancer. Breast CancerRes. Treat. 66: 183-190

38. Vikhanskaya F, Marchini S, Marabese M, Galliera E and Broggini M (2001)P73a overexpression is associated with resistance to treatment with DNA-damaging agents in a human ovarian cancer cell line. Cancer Res. 61: 935-938

39. Sherr CJ (1998) Tumor surveillance via the ARF-p53 pathway. Genes Dev. 12: 2984-2991

40. Balint E, Bates S and Vousden KH (1999) Mdm2 binds p73 alpha without targeting degradation. Oncogene 18: 3923-3929

41. Zeng X, Chen L, Jost CA, Maya R, Keller D, Wang X, Kaelin WG, Oren M, Chen J and Lu H (1999) MDM2 suppresses p73 function without promoting p73 degradation. Mol. Cell. Biol. 19: 3257-3266

42. Stiewe T and PutzerBM (2000) Role of the p53-homologue p73 in E2F1-induced apoptosis. Nat. Genet. 26: 464-469

43. Irwin M, Marin MC, Phillips AC, Seelan RS, Smith DI, Liu W, Flores ER, Tsai KY, Jacks T, Vousden KH and Kaelin WG (2000) Role for the p53 homologue p73 in E2F-1-induced apoptosis. Nature 407: 645-648

44. Lissy NA, Davis PK, Irwin M, Kaelin WG and Dowdy SF (2000) A common E2F-1 and 173 pathway mediates cell death induced by TCR activation. Nature 407: $642-645$

45. Zaika A, Irwin M, Sansome C and Moll UM (2001) Oncogenes Induce and Activate Endogenous p73 Protein. J. Biol. Chem. 276: 11310-11316

46. Putzer BM, Stiewe T, Parssanedjad K, Rega S and Esche H (2000) E1A is sufficient by itself to induce apoptosis independent of $p 53$ and other adenoviral gene products. Cell Death Differ. 7: 177-188
47. DiComo CJ, Gaiddon C and Prives C (1999) p73 function is inhibited by tumorderived p53 mutants in mammalian cells. Mol. Cell. Biol. 19: 1438-1449

48. Marin MC, Jost CA, Brooks LA, Irwin MS, O'Nions J, Tidy JA, James N, McGregor JM, Harwood CA, Yulug IG, Vousden KH, Allday MJ, Gusterson B, Ikawa S, Hinds PW, Crook T and Kaelin WG (2000) A common polymorphism acts as an intragenic modifier of mutant p53 behaviour. Nat. Genet. 25: 47-54

49. Davison TS, Vagner C, Kaghad M, Ayed A, Caput D and Arrowsmith CH (1999) p73 and p63 are homotetramers capable of weak heterotypic interactions with each other but not with p53. J. Biol. Chem. 274: 18709-18714

50. Strano S, Munarriz E, Rossi M, Cristofanelli B, Shaul Y, Castagnoli L, Levine AJ Sacchi A, Cesareni G, Oren M and Blandino G (2000) Physical and functional interaction between p53 mutants and different isoforms of p73. J. Biol. Chem. 275: 29503-29512

51. Gaiddon C, Lokshin M, Ahn J, Zhang T and Prives C (2001) A subset of tumorderived mutant forms of p53 down-regulate p63 and p73 through a direct interaction with the p53 core domain. Mol. Cell. Biol. 21: 1874-1887

52. Cai YC, Yang GY, Nie Y, Wang LD, Zhao X, Song YL, Seril DN, Liao J, Xing EP and Yang CS (2000) Molecular alterations of p73 in human esophagea squamous cell carcinomas: loss of heterozygosity occurs frequently; loss of imprinting and elevation of p73 expression may be related to defective p53. Carcinogenesis 21: 683-689

53. Tschan MP, Grob TJ, Peters UR, Laurenzi VD, Huegli B, Kreuzer K, Schmidt CA Melino G, Fey MF, Tobler A and CajotJF (2000) Enhanced p73 expression during differentiation and complex p73 isoforms in myeloid leukemia. Biochem. Biophys. Res. Commun. 277: 62-65 